\title{
Embolization Therapy
}

National Cancer Institute

\section{Source}

National Cancer Institute. Embolization Therapy. NCI Thesaurus. Code C15230.

A procedure in which substances are injected into blood vessels adjacent to a tumor for the purpose of interrupting the blood flow to the cancer cells. 